\title{
Virulence Characterization and Identification of Maize Lines Resistant to Puccinia sorghi Schwein. Present in the Argentine Corn Belt Region
}

M. A. Darino and L. Rochi, Instituto de Genética "Ewald A. Favret", CICVyA-INTA CC25 (1712) Castelar, Buenos Aires, Argentina; V. V.
Lia, Instituto de Biotecnología, CICVyA-INTA CC25 (1712) Castelar, Buenos Aires, Argentina; E. D. Kreff, Pioneer Hi-Bred International,
Inc., Ruta Nacional 178 km 11 Pergamino, Buenos Aires, Argentina; and M. F. Pergolesi, L. R. Ingala, M. J. Dieguez, and F. Sacco, Instituto de Genética "Ewald A. Favret", CICVyA-INTA CC25 (1712) Castelar, Buenos Aires, Argentina

\begin{abstract}
Darino, M. A., Rochi, L., Lia, V. V., Kreff, E. D., Pergolesi, M. F., Ingala, L. R., Dieguez, M. J., and Sacco, F. 2016. Virulence characterization and identification of maize lines resistant to Puccinia sorghi Schwein. present in the Argentine Corn Belt region. Plant Dis. 100:770-776.

Puccinia sorghi Schwein., the causal agent of maize common rust, is an endemic disease in the Argentine Corn Belt region. Virulence surveys of the pathogen population within the region have not been performed; thus, the understanding of the pathogen population is low and it is difficult to deploy resistance genes that could be effective at controlling the disease. In total, 58 single-uredinial isolates derived from infected maize leaves collected in different locations throughout the Argentine Corn Belt region during 2010 to 2012 were tested on a set of 25 maize lines carrying different $R p$ genes. Maize lines $R p 3-A$ and PIO19802 showed the lowest virulence frequencies (3.4 and $1.7 \%$, respectively) for all tested isolates.

Moreover, the combination in a single genotype of the resistance genes carried by lines Rp3-A and PIO19802 or either of these lines combined with the resistance genes from PIO12345 would confer resistance to all isolates tested. Virulent isolates on maize lines $R p-G, R p 1-K$, and $R p$-GI were most frequent in 2012. Twenty-four virulence phenotypes were identified, with phenotypes TCCG (17.2\%), TTBB $(15.5 \%)$, and TCFG $(10.3 \%)$ being the most common throughout the region. Adult plant resistance associated with hypersensitive response was identified at vegetative stage 6 in maize lines PIO68752, PIO28427, and PIO36420.
\end{abstract}

Maize (Zea mays L.) is one of the most important crops in Argentina, with an average production of about 26 million tons/year (SIIA 2015). The Argentine Corn Belt region is the main production area, with an average of 9 tons/ha (WAR 2014), including the northern part of the province of Buenos Aires, eastern part of the province of Córdoba, southern part of the province of Santa Fe, and western part of the province of Entre Rios. Common rust, caused by Puccinia sorghi Schwein., is an endemic disease in this region. The level of severity is variable, depending on the environmental conditions, the pathotypes present in the pathogen population, and the genotypes of commercial corn hybrids sown each year. The disease can generate corn yield reduction of approximately $6 \%$ for each $10 \%$ rust severity (Pataky 1987b). Common rust can be controlled using fungicides and/or resistance $(R p)$ genes. All known $R p$ genes are race-specific (providing resistance to some but not all races), confer resistance at all growth stages, and usually result in hypersensitive responses (Hulbert 1997). Hooker and coworkers characterized $24 R p$ genes, 16 of which located in the rp1 area in the short arm of chromosome 10 (Hooker 1985). Among them, 14 were considered a series of alleles at a single locus termed $R p l$ and designated as Rpl-A to Rpl-N (Hooker 1985) but detailed genetic and molecular studies that included large testcross progenies for several Rpl heterozygotes showed that this locus is composed by closely linked genes that could be reassorted by recombination. Furthermore, the $R p 1-G$ gene was mapped roughly two map units distal to the other $R p l$ genes and, therefore, was designated as $R p-G$ (Hooker and Saxena 1971; Hulbert and Bennetzen 1991; Saxena and Hooker 1968). The two other genes $R p 5$ and $R p 6$ were designated as separate loci because they recombine frequently with $R p l$ genes

Corresponding author: D. Martin; E-mail: darino.martin@inta.gob.ar

*The $\boldsymbol{e}$-Xtra logo stands for "electronic extra" and indicates that two supplementary figures are published online.

Accepted for publication 23 October 2015.

http://dx.doi.org/10.1094/PDIS-06-15-0639-RE

(C) 2016 The American Phytopathological Society
(Hagan and Hooker 1965; Wilkinson and Hooker 1968). Other Rp loci such as $R p 3$ and $R p 4$ were identified on chromosome 3 and 4, respectively (Hagan and Hooker 1965; Hooker 1963; Russell and Hooker 1962; Wilkinson and Hooker 1968). Differential near-isogenic lines were developed by introgression of $R p$ genes in corn inbred lines R168 or B14 by Hooker and coworkers (Hulbert et al. 1991). Through recombination events, lines carrying two or more $R p$ genes from the rp1 area were constructed and defined as compound $R p$ genes $(\mathrm{Hu}$ and Hulbert 1996). Unfortunately, the set of rust isolates used by Hooker and coworkers to identify each of the $R p$ genes is no longer available (Hulbert et al. 1991). In order to restore a set able to distinguish between $R p$ genes, isolates collected from different locations of North America were tested on the $R p$ differential lines and on inbred lines carrying different $R p l$ genes (Hulbert et al. 1991). However, some groups of $R p$ genes such as Rpl-C, Rpl-L, and Rpl-N;Rpl-E, $R p 1-I$, and Rpl-K; Rpl-A and Rpl-F; and Rpl-H and Rpl-J could not be distinguished by their resistance reaction.

Virulence surveys of $P$. sorghi were performed in the United States to monitor virulence shifts in the pathogen population and to establish single $R p$ genes or compound $R p$ genes useful for breeding programs (Groth et al. 1992; Pataky 1987a; Pataky et al. 2001). For other cereal rusts such as wheat leaf rust ( $P$. triticina Erikss.) and wheat stripe rust $(P$. striiformis f. sp. tritici) similar virulence surveys were performed not only to detect shifts in virulence throughout the years and postulate resistant genes that could be effective to control the rust populations but also to study the diversity in virulence phenotypes and their frequencies within the populations (de Vallavieille-Pope et al. 2012; Kolmer et al. 2008). In Argentina, the first report about races of $P$. sorghi was made by Vallega (1942), where two virulence phenotypes, designated as A and B, were identified using two maize inbred lines as differentials. Between 1996 and 2000 , a set of $21 R p$ genes from four $R p$ loci were evaluated under field conditions against the pathogen population present in two neighboring locations of the Argentine Corn Belt region, Pergamino (northern part of the province of Buenos Aires) and Zavalla (southern part of the province of Santa $\mathrm{Fe}$ ). In this study, only three $R p$ genes (Rp1-N, Rp3-A, and Rp3-C) were highly resistant (Gonzalez 2000). In a subsequent study, 16 single-uredinial isolates of $P$. sorghi were collected from four neighboring locations within the Argentine Corn 
Belt region: Oliveros, Zavalla, and Venado Tuerto (southern part of province of Santa Fe) and Pergamino, and evaluated under greenhouse conditions using a set of seven lines carrying genes $R p 1-D$, $R p 1-E, R p-G, R p 1-H, R p 1-N, R p 4-A$, and $R p-G J F$. Eleven virulence phenotypes were identified, all avirulent on $R p-G$ and $R p$ $G J F$ lines (Gonzalez 2007). However, virulence surveys of the P. sorghi population present in the Argentine Corn Belt that have included isolates from locations across the region have not been performed, making it difficult to understand diversity within the pathogen population and, consequently, deploy $R p$ genes or combinations of them for disease control. The objectives of the present work were to characterize the virulence of the $P$. sorghi population present in the Argentine Corn Belt region by evaluation of 58 $P$. sorghi single-uredinial isolates, collected from the region during 2010 to 2012, on a set of 25 maize lines and to identify $R p$ genes, compound $R p$ genes, and maize inbred lines that could provide resistance to the pathogen population.

\section{Material and Methods}

Plant material. Seed from a set of 25 maize lines were provided by Pioneer Hi-Bred International, Inc. (Pioneer). The set consisted of $16 R p$ differentials carrying single $R p$ genes $R p 1-A, R p 1-B, R p 1-C$, $R p 1-D, R p-G, R p 1-J, R p 1-K, R p 1-M$, and $R p 3-A$ and compound genes $R p-D 5$ (combination of $R p 1-D$ and $R p 5$ genes), $R p-G 5$ (combination of $R p-G$ and $R p 5$ genes), $R p-G I$ (combination of $R p-G$ and $R p 1-I$ genes), Rp-GDJ (combination of Rp-G, Rpl-D and Rpl-J genes), $R p-G 5 J D$ (combination of $R p-G, R p 5, R p 1-J$ and $R p 1-D$ genes), Rpl-JC (combination of Rpl-J and Rpl-C genes), and $R p 1-F J$ (combination of $R p 1-F$ and $R p 1-J$ genes), developed by introgression of the $R p$ genes in the H95 inbred line genetic background by Hulbert et al. (2001) and obtained from the Maize Genetics Cooperation Stock Center. Nine Pioneer-proprietary maize inbred lines (PIO68752, PIO28427, PIO36420, PIO20046, PIO19802, PIO28760, PIO16310, PIO12345, and PIO17570) completed the set.

Collections of $\boldsymbol{P}$. sorghi single-uredinial isolates. The set of maize lines mentioned above was sown in 21 locations of the Argentine Corn Belt region (Fig. 1). In each location, 40 seeds from each line were sown in two 6-m-long rows in randomized order to minimize neighbor effects ( 20 to 30 plants per line were obtained). The set was surrounded by commercial corn hybrids in fields of 5 to 50 ha in size. Plants were exposed only to the natural pathogen population throughout the growth cycle. The disease infection was variable for the same location over the years and, therefore, locations with high levels of rust infection were selected for collection of $P$. sorghi samples. Locations were visited when maize lines reached reproductive stage 1 (R1, silks visible). Four to six leaves containing $P$. sorghi urediospores were collected from maize lines that were severely rusted (infection types [IT] 3 to 4 , see scale below) at each location. The leaves were stored in an opened paper envelope (to let the infected leaves dry) at $4^{\circ} \mathrm{C}$ until spores were harvested for multiplication. Each envelope containing infected leaves from the same maize line collected from one location was considered a sample. In total, 58 samples were collected during the 3 years (Table 1). For each sample, a pustule was selected and urediospores were extracted using a wet swab and inoculated on 10 to 12 two-leaved seedlings of the same maize line where the sample was originally collected. Before inoculation, plants were sprayed with water containing Tween 20 at 4 drops/liter. Inoculated plants were placed in a dark dew chamber overnight at $15^{\circ} \mathrm{C}$ and then moved to a greenhouse ( 15 to $20^{\circ} \mathrm{C}$ with a minimum of $12 \mathrm{~h}$ of natural light), with separated sections to prevent cross contamination. After 12 to 15 days, urediniospores were collected by tapping infected leaves on a paper sheet. Urediospores were dried in a desiccator for 5 days and stored at $4{ }^{\circ} \mathrm{C}$ or liquid nitrogen for their long-term storage. In all, 58 single-uredinial isolates were obtained, one from each sample. A collection consisted in single-uredinial isolates obtained from infected leaves collected the same year.

Evaluation of the $P$. sorgh $i$ isolates on the set of maize lines. The set of 25 maize lines was inoculated with each of the single-uredinial isolates. Five three-leaved seedlings at vegetative stage 2 (V2) were inoculated as described above by spraying a Tween 20 -water suspension of $20 \mathrm{mg}$ of urediospores from each isolate. Each isolate was evaluated in independent sets and two replicates per each isolate were performed. After 12 to 14 days, IT from 0 to 4 were recorded according to the scale proposed for wheat stem rust (P. graminis f. sp. tritici) by Stakman et al. (1962) but adapted to $P$. sorghi, where $0=$ no uredia or other indications of infection, $1=$ small uredia surrounded by necrosis, $2=$ small to medium uredia often surrounded by necrosis or chlorosis, $3=$ medium uredia that can be surrounded by chlorosis, and $4=$ large uredia without surrounding necrosis or chlorosis. IT 0 to 2 were considered avirulent and IT 3 to 4 were considered virulent. Virulence frequencies on each maize line were determined for each collection of isolates and for the total number of isolates tested.

For each maize line, shifts in their observed virulence frequencies for the isolate collections were determined. Because virulence was treated as a binary trait, its distribution on the population could be considered binomial (Welz 1988) and the probability of occurrence of the virulence observed for each isolates' collection was calculated by the binomial distribution

$$
\left(\begin{array}{l}
n \\
k
\end{array}\right) p^{k}(1-p)^{n-k}
$$

where $n$ is the number of isolates tested of each collection, $k$ is the number of virulent isolates, and $p$ is the proportion of virulent isolates from the total of tested isolates. Virulence frequencies for isolate

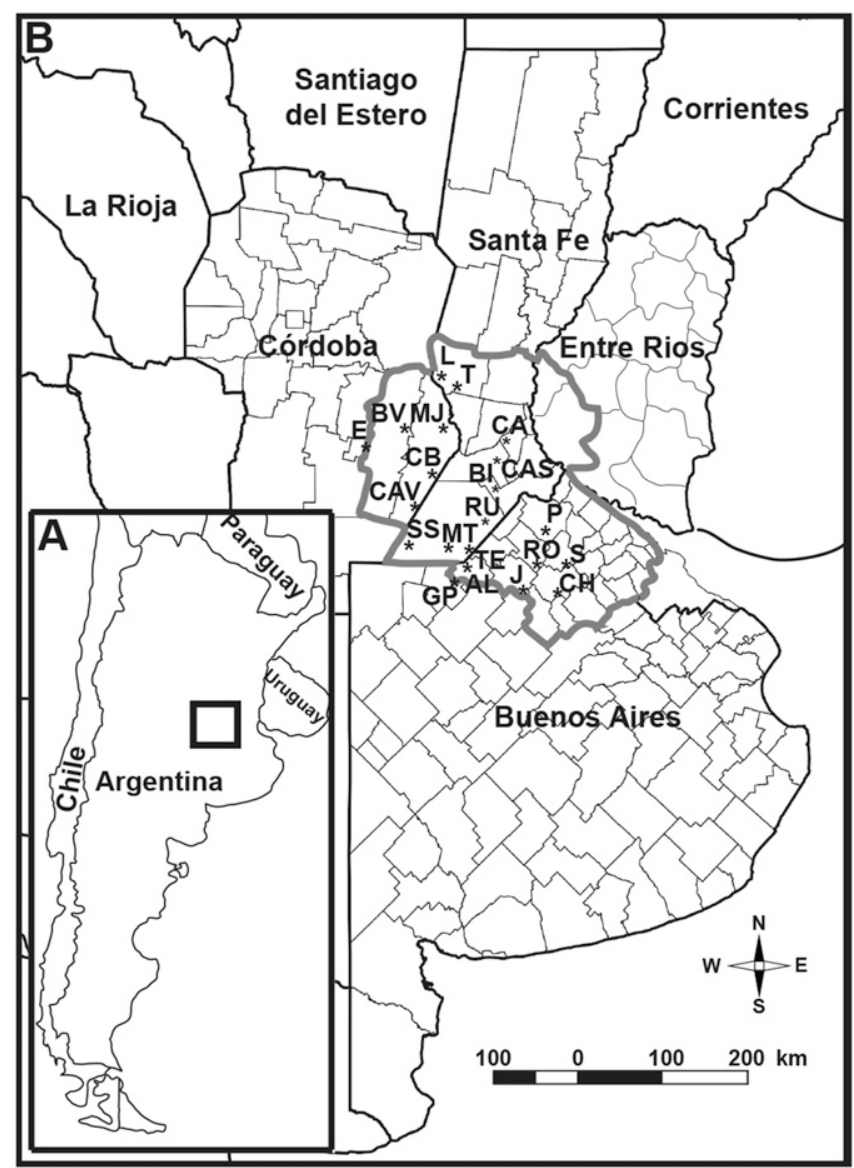

Fig. 1. Field locations where Puccinia sorghi samples were collected. A, Map of Argentina with bordering countries. The rectangle indicates the location of the Argentine Corn Belt region. B, Detailed map of the Argentine Corn Belt region, delimited by a gray line, with the locations where the set of maize lines was sown Buenos Aires: Alberdi (AL), Chacabuco (CH), General Pinto (GP), Junín (J), Pergamino (P), Rojas (RO), and Salto (S); Córdoba: Bell Ville (BV), Cavanagh (CAV), Corral de Bustos (CB), Etruria (E), and Marcos Juárez (MJ); and Santa Fe: Bigand $(\mathrm{BI})$, Carcarañá $(\mathrm{CA})$, Casilda (CAS), El Trébol (T), Landeta (L), María Teresa (MT), Runciman (RU), Sancti Spiritu (SS), and Teodelina (TE). 
collections with a $P \leq 0.05$ were considered to be a deviation of the expected virulence frequency, indicating a shift in the frequency of virulence. Maize lines virulent to all tested isolates were not considered for this analysis.

Table 1. Number of Puccinia sorghi samples collected in 21 locations of the Argentine Corn Belt region each year

\begin{tabular}{|c|c|c|c|c|}
\hline \multirow[b]{2}{*}{ Province } & \multirow[b]{2}{*}{ Location } & \multicolumn{3}{|c|}{ Year $^{\mathbf{a}}$} \\
\hline & & 2010 & 2011 & 2012 \\
\hline \multirow[t]{7}{*}{ Buenos Aires } & Alberdi (AL) & 1 & $\ldots$ & $\ldots$ \\
\hline & Chacabuco $(\mathrm{CH})$ & $\ldots$ & 3 & $\ldots$ \\
\hline & General Pinto (GP) & 2 & 1 & $\ldots$ \\
\hline & Junín (J) & 1 & 1 & 1 \\
\hline & Pergamino $(\mathrm{P})$ & 3 & $\ldots$ & $\ldots$ \\
\hline & Rojas (RO) & 2 & 1 & $\ldots$ \\
\hline & Salto (S) & 2 & 3 & $\ldots$ \\
\hline \multirow[t]{5}{*}{ Córdoba } & Bell Ville (BV) & 2 & $\ldots$ & 1 \\
\hline & Cavanagh (CAV) & $\ldots$ & $\ldots$ & 1 \\
\hline & Corral de Bustos (CB) & $\ldots$ & 4 & 3 \\
\hline & Etruria $(\mathrm{E})$ & 2 & & \\
\hline & Marcos Juárez (MJ) & $\ldots$ & 2 & 4 \\
\hline \multirow[t]{9}{*}{ Santa Fe } & Bigand (BI) & $\ldots$ & 2 & 2 \\
\hline & Carcarañá (CA) & $\ldots$ & 3 & $\ldots$ \\
\hline & Casilda (CAS) & $\ldots$ & 3 & $\ldots$ \\
\hline & El Trébol (T) & 2 & $\ldots$ & $\ldots$ \\
\hline & Landeta $(\mathrm{L})$ & 1 & $\ldots$ & $\ldots$ \\
\hline & Maria Teresa (MT) & $\ldots$ & 2 & $\ldots$ \\
\hline & Runciman (RU) & $\ldots$ & $\ldots$ & 1 \\
\hline & Sancti Spiritu (SS) & 1 & $\ldots$ & $\ldots$ \\
\hline & Teodelina (TE) & 1 & $\ldots$ & $\ldots$ \\
\hline Total & $\ldots$ & 20 & 25 & 13 \\
\hline
\end{tabular}

a During spring and summer 2010 and 2011, conditions were favorable for disease development but, in 2012, extreme drought limited the development of common rust in several locations, reducing the number of collected samples.
Detection of resistance at vegetative stages later than V2 was performed at vegetative stage 6 (V6) using two single-uredinial isolates designated as T10RpD5 and P10PIO16310 with virulence phenotype TCCG. Maize line PIO20046 was used as a susceptible control. Both vegetative stages were defined according to the leaf collar method proposed by Abendroth et al. (2011), where each stage was defined by the number of leaves with visible collar leaf. Both stages were simultaneously infected by inoculation of the uppermost-leaf with visible collar leaf and the next leaf not fully expanded without visible collar leaf. Isolates were inoculated separately on independent sets by spraying a Tween 20 -water suspension of $40 \mathrm{mg}$ of urediospores. Two replicates for each isolate were performed. Eight plants (four plants per 1-liter pot) of each maize line were evaluated in each stage. After 14 days, lines were scored according to the IT scale described above, where IT 0 to 2 corresponded to a resistant reaction and IT 3 to 4 corresponded to a susceptible reaction.

Identification of virulence phenotypes. The virulence phenotype of each $P$. sorghi single-uredinial isolate was determined according to the seedling IT observed on nine differentials lines carrying single $R p$ genes (Rpl-A, Rpl-B, Rpl-C, Rpl-D, Rp-G, Rpl-J, Rpl-K, $R p 1-M$, and $R p 3-A$ ) and five Pioneer inbred lines (PIO68752, PIO19802, PIO28760, PIO12345, and PIO17570). According to the reaction type, Pioneer inbred lines PIO68752, PIO19802, PIO28760, PIO12345, and PIO17570 carry seedling $R p$ genes or alleles different from those present in the $16 R p$ differential lines used in this work. The virulence phenotypes were described by the lettercode proposed by Long and Kolmer (1989) for P. triticina, where a nonvowel letter from $\mathrm{B}$ to $\mathrm{T}$ is used to describe the avirulence/ virulence pattern of each isolate on sets consisting of four host differentials. A four-letter code was established, where the first letter described the avirulence/virulence on $R p 1-A, R p 1-B, R p 1-C$, and $R p 1-D$; the second letter on $R p-G, R p 1-J, R p 1-K$, and Rpl-M; the third letter on $R p 3-A$, PIO19802, PIO28760, and PIO12345; and the fourth letter on PIO17570, PIO68752, and two imaginary lines assumed resistant to all isolates tested. Phenotype frequencies were

Table 2. Number of virulent Puccinia sorghi isolates $(N)$, virulence frequencies $(\%)$, and probability of virulence occurrence $(P)$ for each isolates' collection tested on 25 maize lines $^{\mathrm{a}}$

\begin{tabular}{|c|c|c|c|c|c|c|c|c|c|c|c|}
\hline \multirow[b]{2}{*}{ Maize line } & \multicolumn{3}{|c|}{2010} & \multicolumn{3}{|c|}{2011} & \multicolumn{3}{|c|}{2012} & \multicolumn{2}{|c|}{ Total } \\
\hline & $N$ & $\%$ & $P$ & $N$ & $\%$ & $P$ & $N$ & $\%$ & $P$ & $\bar{N}$ & $\%$ \\
\hline$R p 1-C^{\mathrm{b}}$ & 20 & 100 & $\ldots$ & 25 & 100 & $\ldots$ & 13 & 100 & $\ldots$ & 58 & 100 \\
\hline$R p 1-M^{\mathrm{b}}$ & 20 & 100 & $\ldots$ & 25 & 100 & $\ldots$ & 13 & 100 & $\ldots$ & 58 & 100 \\
\hline PIO20046 & 20 & 100 & $\ldots$ & 22 & 100 & $\ldots$ & 8 & 100 & $\ldots$ & 50 & 100 \\
\hline $\mathrm{PIO} 28427^{\mathrm{b}, \mathrm{c}}$ & 18 & 100 & $\ldots$ & 22 & 100 & $\ldots$ & 13 & 100 & $\ldots$ & 53 & 100 \\
\hline PIO36420 & 20 & 100 & $\ldots$ & 25 & 100 & $\ldots$ & 13 & 100 & $\ldots$ & 58 & 100 \\
\hline$R p 1-A$ & 19 & 95 & 0.272 & 25 & 100 & 0.603 & 13 & 100 & 0.769 & 57 & 98.3 \\
\hline$R p 1-D$ & 19 & 95 & 0.272 & 25 & 100 & 0.603 & 13 & 100 & 0.769 & 57 & 98.3 \\
\hline$R p-D 5$ & 19 & 95 & 0.272 & 25 & 100 & 0.603 & 13 & 100 & 0.769 & 57 & 98.3 \\
\hline PIO16310 & 19 & 95 & 0.272 & 25 & 100 & 0.603 & 13 & 100 & 0.769 & 57 & 98.3 \\
\hline$R p 1-B$ & 17 & 85 & 0.059 & 25 & 100 & 0.277 & 13 & 100 & 0.513 & 55 & 94.8 \\
\hline PIO12345 & 14 & 70 & 0.124 & 16 & 64 & 0.151 & 5 & 38.5 & 0.065 & 35 & 60.3 \\
\hline PIO68752 & 11 & 55 & 0.174 & 16 & 64 & 0.127 & 6 & 46.1 & 0.159 & 33 & 56.8 \\
\hline$R p-G D J$ & 5 & 25 & 0.074 & 11 & 44 & 0.146 & 7 & 53.8 & 0.131 & 23 & 39.6 \\
\hline Rp1-JC & 9 & 45 & 0.159 & 8 & 32 & 0.119 & 6 & 46.1 & 0.196 & 23 & 39.6 \\
\hline Rp1-J & 7 & 35 & 0.177 & 9 & 36 & 0.161 & 6 & 46.1 & 0.182 & 22 & 37.9 \\
\hline$R p 1-F J$ & 7 & 35 & 0.183 & 8 & 32 & 0.154 & 6 & 46.1 & 0.164 & 21 & 36.2 \\
\hline$R p-G$ & 4 & 20 & 0.118 & 7 & 28 & 0.166 & 7 & 53.8 & $0.05^{*}$ & 18 & 31 \\
\hline$R p-G I$ & 4 & 20 & 0.155 & 4 & 16 & 0.078 & 8 & 61.5 & $0.009 * *$ & 16 & 27.5 \\
\hline$R p-G 5 J D$ & 0 & 0 & $0.002 * *$ & 9 & 36 & 0.089 & 6 & 46.1 & 0.064 & 15 & 25.8 \\
\hline$R p 1-K$ & 3 & 15 & 0.192 & 3 & 12 & 0.119 & 6 & 46.1 & $0.028^{*}$ & 12 & 20.6 \\
\hline$R p-G 5$ & 2 & 10 & 0.154 & 6 & 24 & 0.152 & 3 & 23.1 & 0.238 & 11 & 19 \\
\hline PIO28760 & 1 & 5 & 0.098 & 6 & 24 & 0.123 & 3 & 23.1 & 0.218 & 10 & 17.2 \\
\hline PIO17570 & 5 & 25 & $0.032 *$ & 1 & 4 & 0.199 & 0 & 0 & 0.254 & 6 & 10.3 \\
\hline Rp3-A & 1 & 5 & 0.336 & 1 & 4 & 0.361 & 0 & 0 & 0.673 & 2 & 3.4 \\
\hline PIO19802 & 0 & 0 & 0.667 & 1 & 4 & 0.307 & 0 & 0 & 0.769 & 1 & 1.7 \\
\hline Total & 20 & $\ldots$ & $\ldots$ & 25 & $\ldots$ & $\ldots$ & 13 & $\ldots$ & $\ldots$ & 58 & $\ldots$ \\
\hline
\end{tabular}

a Asterisks indicate virulence frequencies that differed significantly from the expected at $P \leq 0.05(*)$ and $P \leq 0.01(* *)$.

b Maize lines susceptible to all tested isolates and, therefore, not considered for the calculation of the probabilities of virulence occurrence for each isolates' collection.

${ }^{\mathrm{c}}$ Maize lines not tested against all isolates due to low germination rates. 
determined for each collection of isolates and for the total of tested isolates.

The avirulence/virulence pattern of each virulence phenotype on the 14 host differentials was converted into a binary code where the avirulence and virulence were classified as 0 and 1 , respectively. Dissimilarity values between phenotypes were established by the Euclidean distance. The dendrogram was derived from the dissimilarity matrix using the clustering unweighted pair-group method with arithmetic means. The dissimilarity matrix and cluster analysis were performed using Power Marker v3.25 (Liu and Muse 2005). The robustness of the dendrogram was evaluated by bootstrap, resampling the binary data by replacement with 1,001 replicates using Power Marker. The bootstrap values were calculated with the CONSENSE program from Phylip v3.69 (Felsenstein 1989). The dendrogram was drawn using FigTree v1.42 (Rambaut 2009).

\section{Results}

Virulence frequencies. Virulence frequencies differed among maize lines for the 58 single-uredinial isolates tested (Table 2; Supplementary Figure S1). Virulence to maize lines $R p 1-C$, Rpl-M, PIO20046, PIO28427, PIO36420, Rpl-A, Rpl-D, $R p-D 5$, PIO16310, and $R p 1-B$ was over $94 \%$ for all tested isolates. Virulence to lines PIO12345 and PIO68752 was 60.3 and $56.8 \%$, respectively. Virulence to lines $R p-G D J, R p 1-J C, R p 1-J$, and $R p 1-F J$ was found between 40 and $35 \%$. Virulence to lines $R p-G, R p-G I$, and $R p$ $G 5 J D$ was found between 31 and $25 \%$. Virulence to lines $R p 1-K$, $R p$-G5, PIO28760, and PIO17570 was found between 21 and $10 \%$. Virulence to lines Rp3-A and PIO19802 was 3.4 and 1.7\%, respectively. Shifts in virulence frequencies for isolate collections were observed for some maize lines (Table 2). Virulence to lines $R p-G$, $R p 1-K$, and $R p-G I$ was detected in the 3 years but highest in 2012 at $53.8,46.1$, and $61.5 \%$, respectively. These frequencies differed significantly from the expected virulence frequencies for those maize lines $(P=0.05,0.028$, and 0.009 , respectively). Virulence to line $R p$ $G 5 J D$ was detected in $2011(36 \%)$ and $2012(46.1 \%)$ but not in 2010 $(0 \%)$, differing significantly from the expected virulence frequency $(P=0.002)$. Virulence to line PIO17570 was only detected in 2010 $(25 \%)$ and $2011(4 \%)$ and the virulence frequency for isolates collected in 2010 differed significantly from the expected virulence frequency $(P=0.032)$. For the other maize lines (Rpl-A, Rpl-D, $R p-D 5$, PIO16310, $R p 1-B$, PIO12345, PIO68752, $R p-G D J, R p 1-$ $J$, Rp1-JC, Rp1-FJ, Rp-G5, PIO28760, Rp3-A, and PIO19802), frequencies of virulence for isolate collections were not significantly different from those expected.

Virulence phenotypes characterization. In all, 24 virulence phenotypes were identified among 58 single-uredinial isolates that were clustered in three virulence groups (Fig. 2; Table 3). Virulence groups were distinguished using a cut-off dissimilarity value of $20 \%$. Group 1, separated from groups 2 and 3 at $25 \%$ dissimilarity, is composed by a single isolate with virulence phenotype JCCQ and differed from the other phenotypes for being avirulent on lines $R p 1-A$ and $R p 1-D$. Group 2, which separated from group 3 at $20 \%$ dissimilarity, consisted of 13 virulence phenotypes that were distinguished from phenotypes of group 3 for being virulent on line PIO12345. Two subgroups ( $2 \mathrm{a}$ and $2 \mathrm{~b}$ ) were observed at $14 \%$ dissimilarity. In addition to being virulent on line PIO12345, phenotypes from subgroup $2 \mathrm{~b}$ were also virulent on line PIO68752. Group 3 consisted of 10 virulence phenotypes avirulent on line PIO12345. Two subgroups ( $3 \mathrm{a}$ and $3 \mathrm{~b}$ ) were observed at $16 \%$ dissimilarity. Phenotypes from subgroup $3 \mathrm{~b}$ were distinguished for being also virulent on lines $R p-G$ and $R p l-J$. In 2010, 13 virulence phenotypes were observed in the 20 tested isolates, with phenotypes TCCG (15\%), TCCQ (15\%), and TTBB (15\%) being the most commonly observed. In 2011, 13 virulence phenotypes were observed in the 25 tested isolates, with phenotypes TCCG $(24 \%)$ and TCFG (12\%) being the most commonly observed. In 2012, seven virulence phenotypes were observed in the 13 tested isolates, and phenotypes TTBB $(30.8 \%)$ and TCFG $(23.1 \%)$ were the most common. Three virulence phenotypes (TCCG, TTBB, and TCFG) were the most common in the 3 -year period, with frequencies of $17.2,15.5$, and
$10.3 \%$, respectively, and were found in areas located in the northern, central, and southern parts of the Corn Belt region (Fig. 1; Table 3). Virulence phenotype TCCB $(6.9 \%)$ was also found throughout the region, whereas phenotypes with $5.2 \%$ frequency were found in central and southern portions (TRBB and TCBB) and northern and southern portions (TCCQ). The less frequent virulence phenotypes $(3.4 \%)$ were always found the same year in two locations in different parts of the region, with the exception of the TTBG phenotype that derived from samples collected in Marcos Juárez, northern portion.

Resistance at growth stage V6. Inbred lines PIO28427 and PIO36420 were susceptible to all tested isolates while inbred line PIO68752 was susceptible to $56.8 \%$ of the isolates tested (Table 2). However, during $P$. sorghi sample collections in the field, these lines at R1 produced IT of 0 to 2 in several locations, indicating the existence of resistance not detected at the seedling stage by the isolates tested (data not shown). When infected at V2 with two isolates with phenotype PCCG (T10RpD5 and P10PIO16310), inbred lines were susceptible with IT of 3 to 4 , characterized by large uredia often coalescent without surrounding chlorosis. However, at stage V6, these three lines were resistant to both isolates with IT of 0 ; to 2 , characterized by hypersensitive flecks mixed with small- to medium-size uredia surrounded by necrotic or chlorotic areas. The control line PIO20046 was susceptible, with IT of 3 to 4 at both stages (Table 4; Supplementary Figure S2).

\section{Discussion}

Two maize lines, one carrying the single $R p$ gene $R p 3-A$ and the inbred line PIO19802, showed the lowest virulence frequencies for all of the single-uredinial isolates tested. The low virulence frequency observed for line $R p 3-A$ agreed with the field evaluations performed by Gonzalez (2000) on a set of 21 single $R p$ genes at two

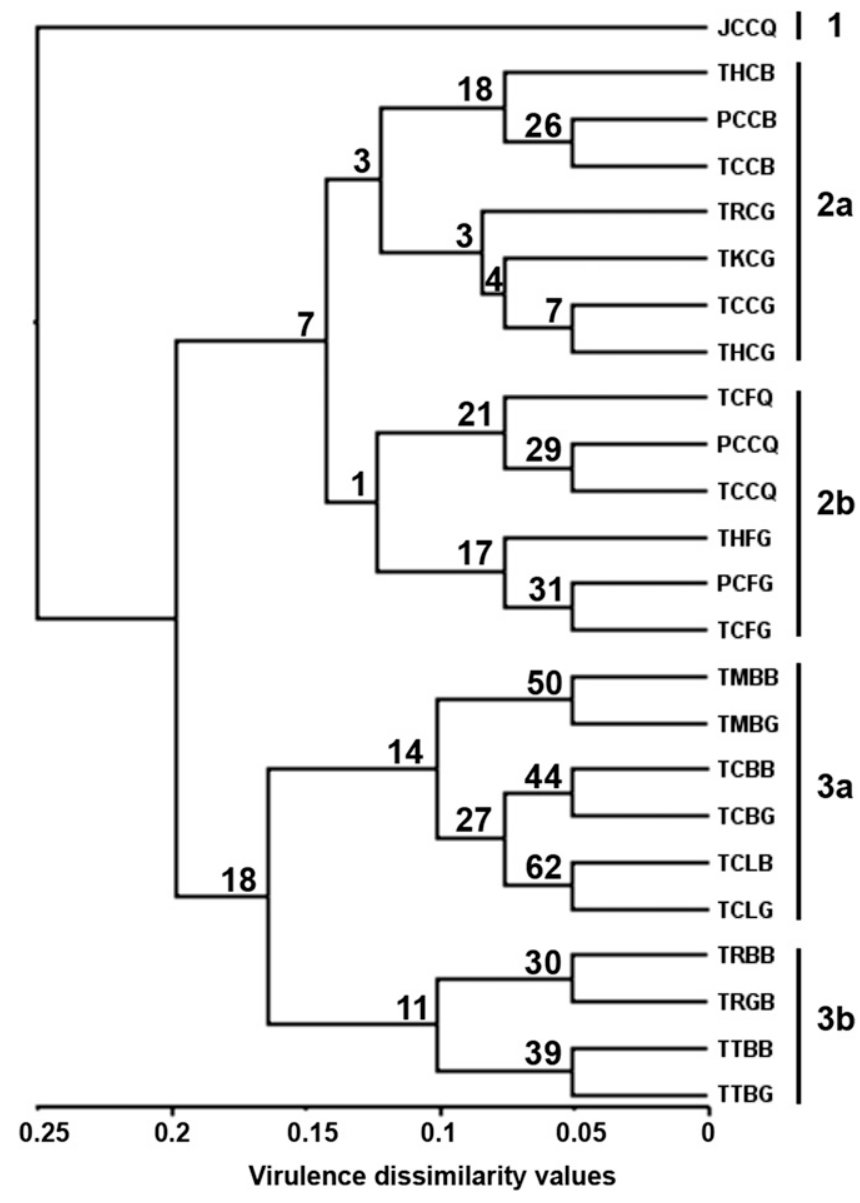

Fig. 2. Unweighted pair-group method with arithmetic means dendrogram based on the avirulence/virulence pattern of 24 virulence phenotypes on 14 maize lines used as differentials. Bootstrap values are indicated above branches. 
neighboring locations of the Argentine Corn Belt region, where the Rp1-N, Rp3-A, and Rp3-C lines had IT 1 and severity of $0 \%$ against the $P$. sorghi population. The combination in a single genotype of the resistance genes carried by lines Rp3-A and PIO19802 would confer resistance to all of the isolates tested because TCLB and TCLG isolates were virulent on line $R p 3-A$ but avirulent on line PIO19802 while isolate TRGB was virulent on line PIO19802 but avirulent on line Rp3-A. Because phenotypes clustered in virulence groups 1 and 2 were virulent on line PIO12345 and avirulent on lines Rp3-A and PIO19802 while phenotypes from virulence group 3 were all avirulent on line PIO12345, the combination of the resistance of line PIO12345 with that of lines Rp3-A or PIO19802 would also confer resistance to all of the isolates tested. Flor (1971) pointed out that cultivars with two or more genes for rust resistance should be less apt to succumb to new races than cultivars possessing a single resistance gene. Therefore, long-lasting resistance may depend on the number of genes which express incompatibility and the ability of the pathogen population to accumulate into single genotypes the entire corresponding virulent genes. The evaluations of the combinations mentioned above throughout several years with different $P$. sorgh $i$ isolates and field testing under a natural pathogen population would determine the durability of these combinations.

Lines PIO17570, PIO28760, Rp-G5, and $R p 1-K$ showed low virulence frequencies, between 21 to $10 \%$ for all of the isolates tested. However, the deployment of the resistance genes from these lines in commercial corn hybrids could most probably not be durable. Isolates with phenotypes TCFG and TTBB, two of the three most frequent during the 3 years, were virulent on line PIO28760 and line $R p 1-K$, respectively. For line $R p-G 5$, which combine single $R p$ genes $R p-G$ and $R p 5$ (Hulbert et al. 2001), the virulence frequencies remained between 10 to $24 \%$ during the 3 years but the increases in the virulence observed on maize line $R p-G$ for isolates from 2012 indicated that the resistance of line $R p-G 5$ could also be not durable. Resistance of the line PIO17570 could also be not durable because four phenotypes

Table 3. Virulence phenotypes, virulence, and phenotype frequencies of 58 Puccinia sorghi single-uredinial isolates derived from infected maize leaves collected in the Argentine Corn Belt region during 2010 to 2012

\begin{tabular}{|c|c|c|c|c|c|c|c|c|c|c|}
\hline \multirow[b]{2}{*}{ Phenotype $^{a}$} & \multirow[b]{2}{*}{ Virulence } & \multicolumn{2}{|c|}{2010} & \multicolumn{2}{|c|}{2011} & \multicolumn{2}{|c|}{2012} & \multicolumn{2}{|c|}{ Total } & \multirow[b]{2}{*}{ Location $^{b}$} \\
\hline & & $N$ & $\%$ & $N$ & $\%$ & $N$ & $\%$ & $N$ & $\%$ & \\
\hline JCCQ & Rp1-B, Rp1-C, Rp1-M, PIO12345, PIO17570, PIO68752 & 1 & 5 & 0 & 0 & 0 & 0 & 1 & 1.7 & $\mathrm{P}$ \\
\hline THCB & Rp1-A, Rp1-B, Rp1-C, Rp1-D, Rp1-J, Rp1-M, PIO12345 & 2 & 10 & 0 & 0 & 0 & 0 & 2 & 3.4 & GP, BV \\
\hline PCCB & $R p 1-A, R p 1-C, R p 1-D, R p 1-M$, PIO12345 & 1 & 5 & 0 & 0 & 0 & 0 & 1 & 1.7 & $\mathrm{~T}$ \\
\hline TCCB & $R p 1-A, R p 1-B, R p 1-C, R p 1-D, R p 1-M, \mathrm{PIO} 12345$ & 1 & 5 & 2 & 8 & 1 & 7.7 & 4 & 6.9 & $\mathrm{~S}, \mathrm{CH}, \mathrm{BV}, \mathrm{BI}$ \\
\hline TRCG & $\begin{array}{l}R p 1-A, R p 1-B, R p 1-C, R p 1-D, R p 1-J, R p-G, R p 1-M, \text { PIO12345, } \\
\quad \text { PIO68752 }\end{array}$ & 0 & 0 & 1 & 4 & 0 & 0 & 1 & 1.7 & $\mathrm{CH}$ \\
\hline TKCG & $\begin{array}{l}R p 1-A, R p 1-B, R p 1-C, R p 1-D, R p 1-J, R p 1-K, R p 1-M, \text { PIO12345, } \\
\quad \text { PIO68752 }\end{array}$ & 0 & 0 & 1 & 4 & 0 & 0 & 1 & 1.7 & CAS \\
\hline TCCG & Rp1-A, Rp1-B, Rp1-C, Rp1-D, Rp1-M, PIO12345, PIO68752 & 3 & 15 & 6 & 24 & 1 & 7.7 & 10 & 17.2 & $\begin{array}{l}\text { S, GP, P, CAV, MJ, } \\
\text { BI, MT, T }\end{array}$ \\
\hline THCG & $\begin{array}{l}R p 1-A, R p 1-B, R p 1-C, R p 1-D, R p 1-J, R p 1-M, \text { PIO12345, } \\
\text { PIO68752 }\end{array}$ & 1 & 5 & 0 & 0 & 0 & 0 & 1 & 1.7 & $\mathrm{~S}$ \\
\hline TCFQ & $\begin{array}{l}R p 1-A, R p 1-B, R p 1-C, R p 1-D, R p 1-M, \text { PIO28760, PIO12345, } \\
\text { PIO17570, PIO68752 }\end{array}$ & 0 & 0 & 1 & 4 & 0 & 0 & 1 & 1.7 & $\mathrm{CA}$ \\
\hline PCCQ & Rp1-A, Rp1-C, Rp1-D, Rp1-M, PIO12345, PIO17570, PIO68752 & 1 & 5 & 0 & 0 & 0 & 0 & 1 & 1.7 & SS \\
\hline TCCQ & $\begin{array}{l}R p 1-A, R p 1-B, R p 1-C, R p 1-D, R p 1-M, \text { PIO12345, PIO17570, } \\
\quad \text { PIO68752 }\end{array}$ & 3 & 15 & 0 & 0 & 0 & 0 & 3 & 5.2 & $\mathrm{~J}, \mathrm{P}, \mathrm{L}$ \\
\hline THFG & $\begin{array}{l}R p 1-A, R p 1-B, R p 1-C, R p 1-D, R p 1-J, R p 1-M, \text { PIO28760, } \\
\text { PIO12345, PIO68752 }\end{array}$ & 0 & 0 & 2 & 8 & 0 & 0 & 2 & 3.4 & $\mathrm{RO}, \mathrm{CB}$ \\
\hline PCFG & $R p 1-A, R p 1-C, R p 1-D, R p 1-M, \mathrm{PIO} 28760, \mathrm{PIO} 12345, \mathrm{PIO} 68752$ & 1 & 5 & 0 & 0 & 0 & 0 & 1 & 1.7 & $\mathrm{E}$ \\
\hline TCFG & $\begin{array}{l}\text { Rp1-A, Rp1-B, Rp1-C, Rp1-D, Rp1-M, PIO28760, PIO12345, } \\
\quad \text { PIO68752 }\end{array}$ & 0 & 0 & 3 & 12 & 3 & 23.1 & 6 & 10.3 & $\mathrm{~J}, \mathrm{CB}, \mathrm{MJ}, \mathrm{BI}, \mathrm{CA}$ \\
\hline TMBB & $R p 1-A, R p 1-B, R p 1-C, R p 1-D, R p-G, R p 1-M$ & 0 & 0 & 0 & 0 & 1 & 7.7 & 1 & 1.7 & RU \\
\hline TMBG & $R p 1-A, R p 1-B, R p 1-C, R p 1-D, R p-G, R p 1-M$, PIO68752 & 0 & 0 & 1 & 4 & 0 & 0 & 1 & 1.7 & $\mathrm{CB}$ \\
\hline TCBB & $R p 1-A, R p 1-B, R p 1-C, R p 1-D, R p 1-M$ & 0 & 0 & 2 & 8 & 1 & 7.7 & 3 & 5.2 & $\mathrm{CB}, \mathrm{BI}, \mathrm{MT}$ \\
\hline TCBG & Rp1-A, Rp1-B, Rp1-C, Rp1-D, Rp1-M, PIO68752 & 1 & 5 & 0 & 0 & 0 & 0 & 1 & 1.7 & $\mathrm{AL}$ \\
\hline TCLB & $R p 1-A, R p 1-B, R p 1-C, R p 1-D, R p 1-M, R p 3-A$ & 1 & 5 & 0 & 0 & 0 & 0 & 1 & 1.7 & $\mathrm{E}$ \\
\hline TCLG & Rp1-A, Rp1-B, Rp1-C, Rp1-D, Rp1-M, Rp3-A, PIO68752 & 0 & 0 & 1 & 4 & 0 & 0 & 1 & 1.7 & $\mathrm{~J}$ \\
\hline TRBB & $R p 1-A, R p 1-B, R p 1-C, R p 1-D, R p 1-J, R p-G, R p 1-M$ & 1 & 5 & 2 & 8 & 0 & 0 & 3 & 5.2 & $\mathrm{~S}, \mathrm{CB}, \mathrm{CAS}$ \\
\hline TRGB & $R p 1-A, R p 1-B, R p 1-C, R p 1-D, R p 1-J, R p-G, R p 1-M$, PIO19802 & 0 & 0 & 1 & 4 & 0 & 0 & 1 & 1.7 & $\mathrm{CH}$ \\
\hline TTBB & $R p 1-A, R p 1-B, R p 1-C, R p 1-D, R p 1-J, R p 1-K, R p-G, R p 1-M$ & 3 & 15 & 2 & 8 & 4 & 30.8 & 9 & 15.5 & $\begin{array}{l}\text { GP, RO, BV, CB, } \\
\text { MJ, CAS, TE }\end{array}$ \\
\hline TTBG & $\begin{array}{l}R p 1-A, R p 1-B, R p 1-C, R p 1-D, R p 1-J, R p 1-K, R p-G, R p 1-M, \\
\quad \text { PIO68752 }\end{array}$ & 0 & 0 & 0 & 0 & 2 & 15.4 & 2 & 3.4 & MJ \\
\hline Total & $\ldots$ & 20 & $\ldots$ & 25 & $\ldots$ & 13 & $\ldots$ & 58 & $\ldots$ & $\ldots$ \\
\hline
\end{tabular}

Table 4. Infection types of four inbred lines inoculated at two vegetative stages with two Puccinia sorghi single-uredinial isolates

\begin{tabular}{|c|c|c|c|c|c|c|c|c|}
\hline \multirow{2}{*}{$\frac{\text { Isolate }}{\text { Leaf stage }}$} & \multicolumn{4}{|c|}{ T10RpD5 } & \multicolumn{4}{|c|}{ P10PIO16310 } \\
\hline & PIO20046 & PIO68752 & PIO28427 & PIO36420 & PIO20046 & PIO68752 & PIO28427 & PIO36420 \\
\hline V2 & 4 & 4 & $34^{-}$ & 4 & 4 & 4 & $34-$ & 4 \\
\hline V6 & 3 & $0 ; 12-$ & $0,12-$ & $0 ; 11+$ & 34 & $0 ; 11+$ & $0 ; 12-$ & $0 ; 11+$ \\
\hline
\end{tabular}


belonging to different virulence groups (TCFQ, PCCQ, and TCCQ from group 2 and JCCQ from group 1) were virulent on this line.

Virulence to maize lines $R p-G, R p l-K$, and $R p-G I$ (combination of single $R p$ genes $R p-G$ and $R p l-I$ where this last one carries the same gene as line Rp1-K; Hulbert et al. 2001) was highest in 2012 and differed significantly from the expected virulence frequencies. It is important to point out that, in a previous study, $16 P$. sorghi isolates collected in the Argentine Corn Belt region resulted in all being avirulent to line Rp-G (Gonzalez 2007). The shift in the virulence on those lines was due to the increase of the frequency of virulence phenotypes TTBB and TTBG that are virulent on lines $R p-G$ and Rpl$K$. Something similar was observed for line $R p-G 5 J D$ (combination of single $R p$ genes $R p-G, R p 5$, Rpl-J, and $R p 1-D$; Hulbert et al. 2001 ), which was resistant to all isolates tested in 2010. However, virulent isolates on line $R p-G 5 J D$ that appeared during the following years could have originated on isolates virulent on lines $R p$ G5, Rpl-D, and Rpl-J that were found during the 3 years. Indeed, for $P$. triticina and $P$. sorghi rust populations in the United States and the $P$. striiformis f. sp. tritici population in France, virulence shifts over the years were observed for resistance genes deployed in commercial host varieties as a consequence of the selection pressure on the pathogen populations (de Vallavieille-Pope et al. 2012; Kolmer et al. 2008, Pataky et al. 2001). Shifts in the virulence observed for single $R p$ genes $R p-G$ and $R p l-K$ and compound $R p$ genes $R p-G I$ and $R p-G 5 J D$ could be a consequence of their presence in commercial corn hybrids; however, the postulation of $R p$ genes in the genotypes of commercial corn is needed to test this hypothesis.

In all, 24 different virulence phenotypes were identified among 58 $P$. sorghi isolates that were clustered in three virulence groups, where two subgroups were observed in groups 2 and 3, suggesting an evolution of the pathogen on related maize hybrids. $P$. sorghi reproduces on maize by asexual reproduction and a sexual phase can occur on the alternate host, Oxalis corniculata L. (Arthur 1934). Godoy and Bruni (1952) reported the occurrence of the sexual phase in Argentina. They collected $O$. corniculata leaves carrying aeciospores that successfully infected maize seedlings and also were able to infect $O$. corniculata leaves using teliospores from maize. Therefore, the variation observed in the pathogen could be explained by different mechanisms, including mutations and sexual recombination. Concerning host variation, hybrid seed are almost exclusively provided by different seed companies. The evaluation of the set of isolates at seedling stage on different corn hybrids from Pioneer, DeKalb, and Syngenta companies suggests the presence of different resistance genetic backgrounds and specialization of some virulence groups and subgroups for certain corn hybrids (M. Darino, unpublished data).

Virulence phenotypes TCCG (17.2\%), TTBB (15.5\%), and TCFG $(10.3 \%)$ were the most commonly observed during the 3-year period and were collected throughout the Corn Belt region. With the exception of the two isolates with the TTBG phenotype collected in Marcos Juárez, isolates with the same virulence phenotype were collected in different parts of the region, suggesting that the pathogen can be easily dispersed by wind because the Argentine Corn Belt is a flat region with quite similar agroecological conditions that can be considered as an epidemiological unit for P. sorghi.

Adult plant resistance (APR) associated with hypersensitive response was identified at V6 in maize inbred lines PIO68752, PIO28427, and PIO36420. This resistance resembles the APR reported for the pathosystem wheat (Triticum aestivum L.)-wheat leaf rust (P. triticina Erikss), where resistance can initiate at any growth stage postseedling (first and second leaves) but generally reaches its highest expression on flag leaves (Samborski 1985). It is usually conferred by race-specific resistant genes that provide resistance to some but not all races and usually express hypersensitive response (McIntosh et al. 1995). The existence of APR in maize associated with hypersensitive response has not been reported but the resistance observed in lines PIO68752, PIO28427, and PIO36420 at V6 is clear evidence of its existence for the pathosystem maize-common rust. Van Dyke and Hooker (1968) reported an unusual reaction for the $R p 4-B$ gene to different $P$. sorghi isolates at V4 stage that was called Z-type. This reaction consists of resistant flecking at the tip of leaves and development of large, susceptible uredia at the leaf portion that were in a leaf whorl at the time of inoculation, and they postulated that the Z-type reaction is determined by the age and maturation of leaf tissue. It should be mentioned that leaves inoculated at V6 stage, especially those without visible collar leaf, on lines PIO68752, PIO28427, and PIO36420 showed a tendency to develop small- to medium-resistant uredia at the base of leaf and resistant flecking to the tip of the leaf similar to some extent to the Z-type (M. Darino, unpublished data). Furthermore, inoculations of these lines at V4 stage using the two PCCG isolates used in this work allowed the detection of the resistance observed at V6 stage. However, it is not conclusive whether the Z-type-like reaction observed in the present study associated with leaf stage is different from the Z-type reaction described by Van Dyke and Hooker (1968) on gene Rp4-B. More detailed studies are needed to determine whether the Z-type reaction on gene $R p 4-B$ is a type of APR.

\section{Acknowledgments}

We thank Pioneer Hi-Bred International, Inc. for the Ph.D. scholarship and grant (CAT 2895 INTA-Pioneer Hi Bred International) to M. A. Darino that enabled this study; M. E. Lopez from Buenos Aires Grain Exchange for providing the map of the Argentine Corn Belt region; and C. Romero from INTA for greenhouse assistance.

\section{Literature Cited}

Abendroth, L. J., Elmore, R. W., Boyer, M. J., and Marlay, S. K. 2011. Corn Growth and Development. PMR 1009. Iowa State University, Ames.

Arthur, J. C. 1934. Manual of the Rusts in United States and Canada. Purdue Research Foundation, Lafayette, IN.

de Vallavieille-Pope, C., Ali, S., Leconte, M., Enjalbert, J., Delos, M., and Rouzet, J. 2012. Virulence dynamics and regional structuring of Puccinia striiformis f. sp. tritici in France between 1984 and 2009. Plant Dis. 96:131-140.

Felsenstein, J. 1989. PHYLIP-Phylogeny inference package (version 3.2). Cladistics 5:164-166.

Flor, H. H. 1971. Current status of the gene-for-gene concept. Annu. Rev Phytopathol. 9:275-296.

Godoy, E. F., and Bruni, O. 1952. Ciclo evolutivo de las royas del lino (Melampsora lini) y del maíz (Puccinia sorghi) en la Argentina. Rev. Argentina Agron. 19:21-34.

Gonzalez, M. 2000. First report of virulence in Argentine populations of Puccinia sorghi to $R p$ resistance genes in corn. Plant Dis. 84:921.

Gonzalez, M. 2007. Caracterización de factores de resistencia y virulencia en la interacción Zea mays-Puccinia sorghi. Ph.D. dissertation, Universidad Nacional de Córdoba, Facultad de Ciencias Agropecuarias, Córdoba, Argentina.

Groth, J. V., Pataky, J. K., and Gingera, G. R. 1992. Virulence in eastern North American populations of Puccinia sorghi to $R p$ resistance genes in corn. Plant Dis. 76:1140-1144

Hagan, W. L., and Hooker, A. L. 1965. Genetics of reaction to Puccinia sorghi in eleven corn inbred lines from Central and South America. Phytopathology 55:193-197.

Hooker, A. L. 1963. A second major gene locus in corn conditioning resistance to Puccinia sorghi. Phytopathology 53:221-223.

Hooker, A. L. 1985. Corn and sorghum rusts. Pages 207-236 in: The Cereal Rusts A. Roelfs and W. Bushnell, eds. Academic Press, New York.

Hooker, A. L., and Saxena, K. M. S. 1971. Genetics of disease resistance in plants. Annu. Rev. Genet. 5:407-424.

Hu, G., and Hulbert, S. 1996. Construction of 'compound' rust resistance genes in maize. Euphytica 87:45-51.

Hulbert, S. H. 1997. Structure and evolution of the rp1 complex conferring rust resistance in maize. Annu. Rev. Phytopathol. 35:293-310.

Hulbert, S. H., and Bennetzen, J. L. 1991. Recombination at the Rpl locus of maize. Mol. Gen. Genet. 226:377-382.

Hulbert, S. H., Lyons, P. C., and Bennetzen, J. L. 1991. Reactions of maize lines carrying $R p$ resistance genes to isolates of the common rust pathogen, Puccinia sorghi. Plant Dis. 75:1130-1133.

Hulbert, S. H., Webb, C. A., and Smith, S. M. 2001. A modified set of $R p$ differential lines. Maize Genet. Coop. News Lett. 75:40.

Kolmer, J. A., Long, D. L., and Hughes, M. E. 2008. Physiologic specialization of Puccinia triticina on wheat in the United States in 2006. Plant Dis. 92: 1241-1246.

Liu, K., and Muse, S. V. 2005. PowerMarker: An integrated analysis environment for genetic marker analysis. Bioinformatics 21:2128-2129.

Long, D. L., and Kolmer, J. A. 1989. A North American system of nomenclature for Puccinia recondita f. sp. tritici. Phytopathology 79:525-529.

McIntosh, R. A., Wellings, C. R., and Park, R. F. 1995. Wheat Rusts: An Atlas of Resistance Genes. CSIRO Publishing, East Melbourne, Australia.

Pataky, J. K. 1987a. Reaction of sweet corn germplasm to common rust and an evaluation of $R p$ resistance in Illinois. Plant Dis. 71:824-828. 
Pataky, J. K. 1987b. Quantitative relationship between sweet corn yield and common rust, Puccinia sorghi. Phytopathology 77:1066-1071.

Pataky, J. K., Pate, M. C., and Hulbert, S. H. 2001. Resistance genes in the $r p 1$ region of maize effective against Puccinia sorghi virulent on the Rp1-D gene in North America. Plant Dis. 85:165-168.

Rambaut, A. 2009. FigTree v1.4.2: Tree figure drawing tool. Online publication. http://tree.bio.ed.ac.uk/software/figtree/

Russell, W. A., and Hooker, A. L. 1962. Location of genes determining resistance to Puccinia sorghi Schw. in corn inbred lines. Crop Sci. 2:477-480.

Samborski, D. J. 1985. Wheat leaf rust. Pages 39-59 in: The Cereal Rusts. A. Roelfs, and W. Bushnell, eds. Academic Press, New York.

Saxena, K. M. S., and Hooker, A. L. 1968. On the structure of a gene for disease resistance in maize. Proc. Natl. Acad. Sci. USA 61:1300-1305.

SIIA. 2015. Siembra, cosecha, producción y rendimiento. Sistema integrado de información agropecuaria. Ministerio de Agricultura, Ganadería y Pesca. Online publication. http://www.siia.gov.ar/_apps/siia/estimaciones/ estima2.php
Stakman, E. C., Stewart, D. M., and Loegering, W. Q. 1962. Identification of physiologic races of Puccinia graminis var. tritici. U.S. Dep Agric. Agric. Res. Serv. E617.

Vallega, J. 1942. Observaciones preliminares sobre especialización fisiológica de Puccinia sorghi en Argentina. Pages 14-16 in: Anales del instituto fitotécnico de Santa Catalina. J. Vallega, ed. Universidad de la Plata, La Plata, Buenos Aires, Argentina.

Van Dyke, C. G., and Hooker, A. L. 1968. The Z reaction in corn to Puccinia sorghi. Phytopathology 59:33-36.

WAR. 2014. Weekly Agricultural Report. Buenos Aires Grain Exchange, Buenos Aires, Argentina. Online publication. http://www.bolsadecereales.org/index. php?lang=ingles

Welz, G. 1988. Analysis of virulence in pathogen populations. Pages 165-178 in: Experimental Techniques in Plant Disease Epidemiology. J. Kranz and J. Rotem, eds. Springer, Berlin, Heidelberg, New York.

Wilkinson, D. R., and Hooker, A. L. 1968. Genetics reaction to Puccinia sorghi in ten corn inbred lines from Africa and Europe. Phytopathology 58:605-608. 